\title{
Olhares sobre a alimentação contemporânea: a gastro-anomia e os corpos de Botero
}

\author{
Looking at contemporary food: Gastro-anomy \\ and Botero's bodies
}

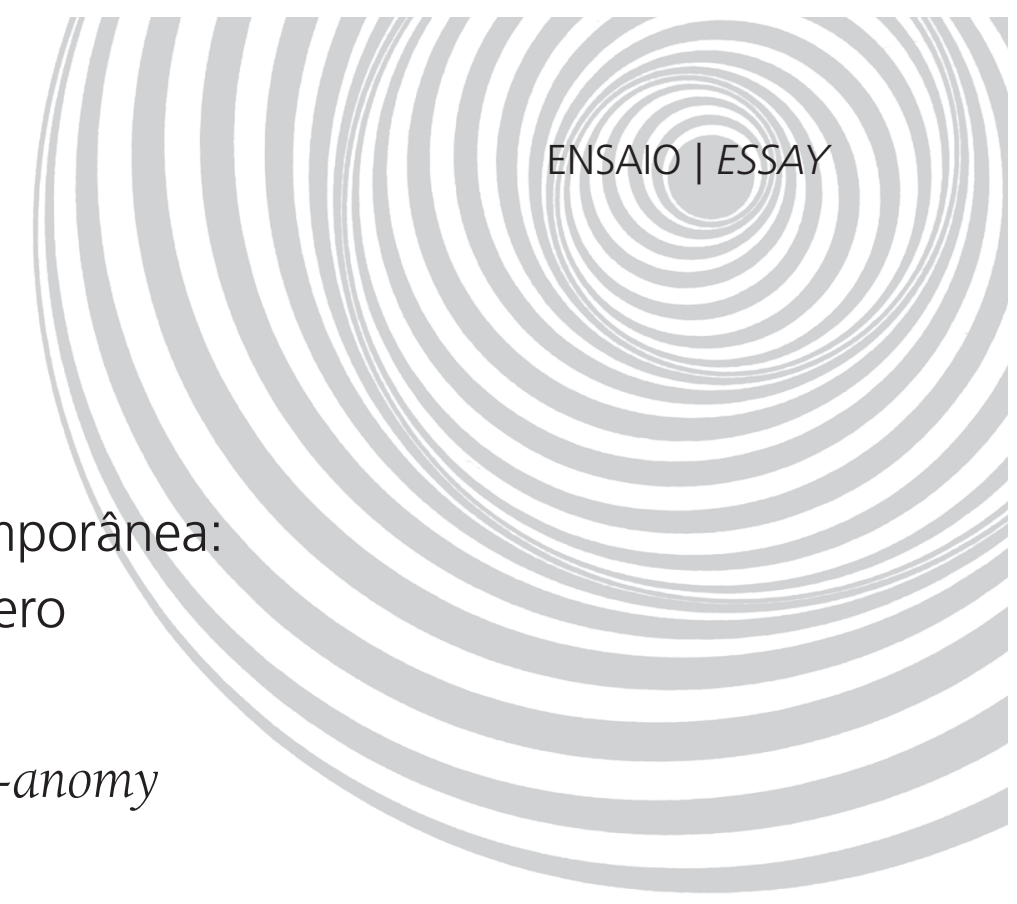

Michelle MEDEIROS

Alex GALENO ${ }^{1}$

\section{R E S U M O}

O excesso de discursos e informação em torno do tema da alimentação gera um cenário em que o comensal já não sabe como decidir pelo que comer. O sociólogo francês Claude Fischler, partindo do conceito durkheimiano, criou o neologismo gastro-anomia para falar sobre o paradoxo que vivenciamos frente à alimentação contemporânea: nunca soubemos tanto sobre os efeitos da alimentação sobre o corpo e, curiosamente, nunca tivemos tantos problemas de saúde relacionados a ela. É sobre este fenômeno gastro-anômico que trata o presente ensaio. Como a anomia se apresenta na sociedade contemporânea quando o assunto é alimentação? Como nutricionistas entendem esta questão? A arte, por realizar a síntese das propriedades intrínsecas da sociedade, foi utilizada como fio condutor das reflexões. O ponto de partida foi análise de duas obras de épocas distintas: Idade Média e contemporaneidade. O casal Arnolfini representado por Jan van Eyck é uma obra que data do século XV, época em que o discurso médico e o religioso eram aqueles que majoritariamente regiam as escolhas alimentares dos indivíduos. A paródia de Botero, por sua vez, traz à tona corpos volumosos, como uma referência ao excesso: o excesso de informações com que se depara o comensal hoje.

Termos de indexação: Alimentação. Arte. Comportamento alimentar.

A B S T R A C T

Excess discourses and information on food results in commensals not knowing what to eat. The Durkheim concept led the French sociologist Claude Fischler to create the neologism gastro-anomy to refer to the paradox that we face today regarding food: we have never known so much about the effects of food on the body and, curiously, we have never had so many food-related health problems. The present essay is about this gastro-anomy phenomenon. How does anomy present itself in today's society with respect to food? How do dieticians understand this issue? Since art synthesizes the intrinsic properties of a society, these reflections

${ }^{1}$ Universidade Federal do Rio Grande do Norte, Centro de Ciências Humanas, Letras e Artes, Programa de Pós-Graduação em Ciências Sociais. Campus das Ciências da Saúde, Av. Gal. Gustavo Cordeiro de Farias, s/n., Petrópolis, 59012-570, Natal, RN Brasil. Correspondência para/Correspondence to: M MEDEIROS.E-mail: <medeiros.michelle@hotmail.com>. 
466 M MEDEIROS \& A GALENO

were guided by art. We started off by analyzing two works from very different time periods: the Middle Ages and today. The Arnolfini couple represented by Jan van Eyck is a work from the 15th century, time when the medical and religious discourse mostly determined people's food choices. On the other hand, Botero's parody elicits plump bodies in reference to excess: the excess information available to commensals nowadays.

Indexing terms: Food. Art. Feeding behavior.

\section{A gastro-anomia: diagnóstico do corpo doente}

A situação da modernidade nos apresenta um paradoxo: nunca soubemos tanto sobre os efeitos da alimentação sobre o corpo e, curiosamente, nunca tivemos tantos problemas de saúde relacionados a ela. Excesso de peso e obesidade são bons exemplos. Dados da World Health Organization ${ }^{1}$ mostram que, em 2008, 1,5 bilhões de adultos apresentavam sobrepeso. Destes, mais de 200 milhões de homens e quase 300 milhões de mulheres estavam obesos. No Brasil, a Pesquisa de Orçamentos Familiares (POF), de 2008 e 2009, mostra que o quadro não é mais a fuga da normalidade: "excesso de peso foi diagnosticado em cerca de metade dos homens e das mulheres"2 (p.23).

É verdade que vivemos em uma época na qual nunca tivemos tanta informação sobre alimentação. Os dados acima, todavia, nos fazem pensar que o excesso de informação parece não nos ajudar a comer melhor. Antes, poderia gerar uma cacofonia de discursos, não raro dissonantes: dietéticos, identitários, publicitários, éticos... . A modernidade alimentar criou uma situação em que o campo de decisão alimentar do comensal se apresenta amplo. A nós é concedida autonomia para escolher e a questão do dia passa a ser outra: "o que escolher?". Não sabemos.

Diria Claude Fischler que a autonomia crescente é portadora de anomia ${ }^{3}$. No estado de anomia, devido a uma divisão do trabalho que não é solidária, as formas de agir não encontram espaço para serem replicadas e tornarem-se hábitos e, em seguida, regras de conduta. As forças reguladoras externas ao indivíduo já não conseguem sustentar a regra. Há uma infinidade delas sob o mesmo tema sendo enunciadas ao mesmo tempo por órgãos que não estão em contato. O que se diz passa a ser vago e geral. Sem regras, "já não se sabe o que é possível e o que não o é, o que é justo e o que é injusto, quais são as reivindicações e as esperanças legítimas, quais são as que ultrapassam as medidas"4 (pp.321).

Já não se sabe, ademais, o que se deve e o que não se deve comer. As opiniões fragmentadas já não formam um todo solidário ${ }^{5}$. Para este estado de ausência de regras concernentes à alimentação, Claude Fischler recorreu ao conceito durkheimiano de anomia e criou o neologismo gastro-anomia.

O excesso de fragmentação dos grupos sociais e de individualismos modernos tem contribuído para uma crise civilizatória sem precedentes. Cada vez mais a sociedade se assemelha a um ajuntamento de interesses particulares e individuais, comprometendo a dinâmica de cooperação e coesão social. Para Durkheim ${ }^{6}$ a sociedade necessita de um "cimento social" que religue as partes separadas e configure uma totalidade orgânica. Ao analisarmos a sociedade atual, podemos notar que vivemos um paradoxo. Por um lado, reproduzimos valores e comportamentos coletivos, sobretudo, a partir das imagens midiáticas e padrões de consumo. O corpo a ser visto e consumido simbolicamente age coercivamente sobre aquele que está fora dos padrões. Estar acima do peso, portanto, é não se adequar ao padrão moral imagético da sociedade contemporânea.

Por outro lado, a exigência do padrão do culto ao corpo belo e magro recai sobre a responsabilidade do indivíduo. O corpo que deve emagrecer e a responsabilidade de tornar-se belo apresentam-se como deveres morais individuais e não responsabilidade coletiva. É evidente que a anomia também se verifica quando presenciamos 
a obesidade enquanto pandemia na sociedade e suas consequências para a saúde dos indivíduos. Corpos doentes pela fadiga depressiva da melancolia diária, heranças cultural e genética das famílias e as consequentes doenças crônicas nãotransmissíveis, são exemplos de doenças contemporâneas que atestam tal anomia. O que não significa que corpos demasiadamente magros ou anoréxicos também não se constituam em corpos que fogem ao padrão coletivo. Enfim, os dois polos expressam sintomas de uma cultura anômica.

Em algumas de suas obras - como, por exemplo, El (H)omnívoro e Comer, esta última com edição em português -, e em entrevista concedida à antropóloga Mirian Goldenberg, Fischler discorre mais sobre essa categoria, e a apresenta - sem desconsiderar outros condicionantes que incidem sobre o tema -, como uma das vias de se analisar "as dificuldades que as pessoas têm para lidar com a complexidade que se tornaram as práticas e representações alimentares na sociedade contemporânea"7 (p.237).

A gastro-anomia é o diagnóstico do corpo doente. Gera um conflito ansioso capaz de afetar o corpo. De anoréxicos a obesos, a desconfortante liberdade anômica gera padrões alimentares que retratam a crise da alimentação na contemporaneidade. É sobre este fenômeno gastro-anômico que trata este ensaio. Como a anomia se retrata na sociedade contemporânea? Como conviver com ela?

\section{Por que a arte?}

Entendendo a arte como imagem daquilo que somos e construímos como humanos, como disse certa vez Lévi-Strauss ${ }^{8}$, tomaremos como ponto da partida a comparação de duas obras de arte: a clássica pintura do artista plástico flamengo Jan van Eyck, Os esponsais dos Arnolfini, pintado em 1434, e sua paródia, o quadro do colombiano
Fernando Botero(2), Matrimonio Arnolfini segun van Eyck, 1997 (Figura 1). As obras, em verdade, serão pretextos para acessar o tema da gastro-anomia. A reflexão que instiga este trabalho é a seguinte: o que a ciência da Nutrição poderia fazer para ajudar os comensais a conviver neste ambiente gastro-anômico?

Não desconsideremos que na arte há um pensamento profundo sobre a condição humana ${ }^{9}$. A arte fala sobre nós. Por isso, ela pode servir-nos como meio de instrução da realidade. As obras de Botero em suas figuras volumosas oferecem-nos a possibilidade de pensar uma

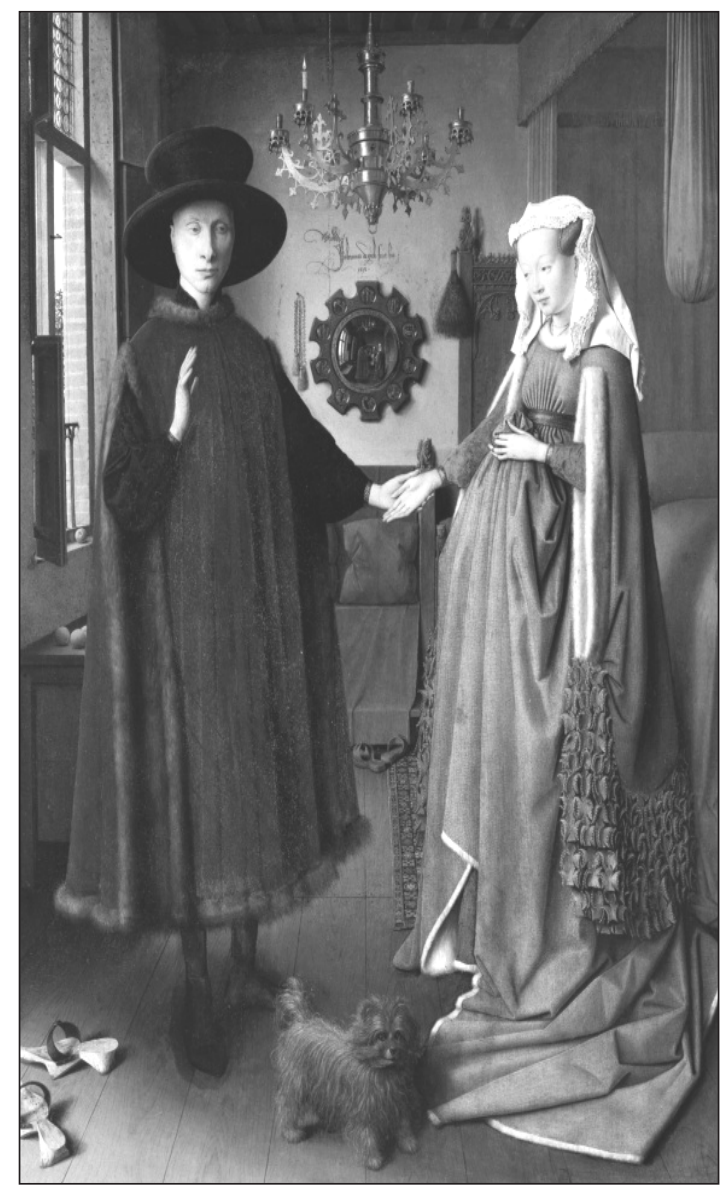

Figura 1. Jan van Eyck, Os esponsais dos Arnolfini, 1434. Fonte: <http://www.nationalgallery.org.uk>.

\footnotetext{
$\overline{2}$ A imagem de Fernando Botero não foi adicionada ao ensaio, pois, encontra-se protegida por direitos autorais, segundo a Lei nº 9.610 de 1998.
} 
sociedade do excesso, com corpos que retratam sua época. Seguindo a proposta de Lévi-Strauss de "modelos reduzidos" poderíamos dizer, portanto, que a obra em questão realiza a síntese das propriedades intrínsecas da sociedade, espacialmente e temporalmente ${ }^{10}$. Opera-se pela metáfora: por meio da parte procede-se à compreensão do todo.

\section{O excesso como anomia}

O casal Arnolfini representado por Jan van Eyck é uma obra que data da Idade Média, representa provavelmente o momento do casamento do mercador italiano Giovanni Arnolfini e sua noiva Jeanne de Chenany ${ }^{11}$. A obra, de 1434, marca no mundo das técnicas pictóricas o emprego da pintura a óleo, idealizada por van Eyck. O uso do óleo ao invés do ovo na preparação de tintas, como antes se utilizava, apresentava ao artista a possibilidade de trabalhar mais devagar, logo, com mais exatidão e detalhes. Não à toa Van Eyck atingiu seu triunfo na pintura de retratos: telas pintadas com minúcia e precisão retratando o mundo fora delas, como parece ser o caso da representação dos Arnolfini e sua residência.

Durante este período grande parte dos conhecimentos médicos na Europa partia da Igreja, que tratava o corpo como algo não relevante: tudo deveria ser feito em prol da alma e da vida depois da morte ${ }^{12}$. As prerrogativas em relação ao jejum e os alertas quanto ao pecado da gula criavam nos fiéis uma postura de temperança ou, quando não, levava-os a aderir a uma dieta tão restritiva que poderia levá-los à morte, como de fato ocorreu. Conforme Bruno Laurioux, historiador medievalista da alimentação, a religião ocupava o primeiro lugar dentre as normas culturais que incidiam sobre o discurso alimentar na Idade Média ${ }^{13}$.

O artista fornece-nos pistas da religiosidade do casal. Tome-se como exemplo o espelho retratado no fundo da tela. Os medalhões que o contornam representam cenas bíblicas. Além do nome da obra, há sinais nela que indicam que o tema é uma cerimônia religiosa. O cão pode ser símbolo de fidelidade ${ }^{14}$; as laranjas como símbolo de pureza original, como também pensa Carlos Fuentes em El naranjo; o lustre tem apenas uma vela acesa, o que pode indicar provavelmente a espiritualidade do ato (Além disso, era costume em Bruges, cidade belga onde vivia o casal, manter acesa uma vela na noite do casamento); os personagens de mãos dadas no centro da pintura denotam que o tema principal da obra era a união do casal ${ }^{15}$, o que é reforçado pela maneira como o casal dispõe de suas mãos: "a jovem acaba de pôr sua mão direita sobre a esquerda de Arnolfini, e este parece estar prestes a colocar sua mão direita na esquerda dela, como símbolo solene de sua união"11 (p.240). O reflexo no espelho parece nos indicar que Giovanni recebia pessoas que chegavam para a cerimônia. Os sinais nos dão indicativos da religiosidade do casal que, possivelmente, dava ouvidos ao discurso da Igreja quanto à moderação na alimentação. Esta hipótese seria sustentada pelos seus corpos longilíneos e esguios.

A partir do século XIII o discurso hegemônico da religião passa a caminhar ao lado daquele médico, ofício que começava a passar pelo processo de profissionalização. Aparecem as universidades (Universidade de Bolonha, de Paris e de Montpellier), onde se discutiam principalmente as traduções das obras de Galeno, que entendia a dietética, por exemplo, como uso adequado das coisas não naturais: clima, exercícios físicos, banhos, sono, atividade sexual, emoções e dieta.

Vale ressaltar aqui que embora as ideias galênicas se constituíssem em cânone para a formação médica, assim como o modelo hipocrático, séculos mais tarde (XV-XVI) surgia o médico Paracelso que advogava a complementaridade entre os saberes herdeiros da alquimia e os saberes acadêmicos à época. Sem esquecermos, ainda, da própria filosofia que, segundo Jung, Paracelso compreendia "muito mais como vivência do que raciocínio"16 (p. 19). A partir de Carl Gustav Jung, em $O$ Espírito na arte e na ciência ${ }^{17}$, constatamos a singularidade das ideias deste importante alqui- 
mista e médico quando Jung mostra que em seu pensamento a medicina deveria guiar-se não apenas em um foco medicamentoso e naquilo que era considerado o estritamente científico, mas, relacionar com os elementos da natureza e do cosmos.

Jung, por exemplo, destaca, em Paracelso, que o médico ao fazer diagnóstico, prognóstico, etiologia - assim como, a farmacologia e a manipulação dos medicamentos -, deve relacioná-los com os dados da astrologia. Percebemos, portanto, a singularidade de Paracelso no processo de compreensão das ciências médicas. Um saber mais amplo para a formação do médico e, por isso, muito contestado. Aliás, poderíamos dizer que tal singularidade também é percebida no próprio Jung, no que tange ao campo paradigmático da ciência hegemonicamente constituída por métodos cartesianos de separação entre objetividade e subjetividade ou entre sujeito e o objeto de sua investigação. Neste particular, certamente, não foi por acaso que Jung resolveu resgatar a figura de Paracelso, isto é, resgatar um saber rebelde de outro para também destacar o seu. A alquimia e a astrologia, constituíam - juntamente com o saber científico que se estabelecia neste período da história -, o discurso médico. Ou como diria Michel Foucault em As palavras e as coisas, uma episteme nascente à época.

Há neste período intensa produção de textos dietéticos, como Le Régime Du corps de Aldebrandin de Sienne, Tacuinum Sanitatis de lbn Butlan e outros. Tais textos foram amplamente difundidos na Idade Média e estavam presentes nas casas das famílias aristocráticas, como era o caso do casal Arnolfini. As peças do mobiliário e o feito de encomendarem um retrato são indicativos do poder econômico do casal.

O discurso médico e o religioso eram aqueles que na época regiam em grande medida as escolhas dos indivíduos. Percebe-se que, mesmo neste contexto, não havia uma teoria dietética que unificasse a variedade de práticas alimen$\operatorname{tares}^{17}$. O que podemos assegurar é que a quanti- dade de informações - se pensarmos no terceiro polo da comunicação, o telemático informacional, enunciado por Pierre Lévy ${ }^{18}$, isto é, aquelas informações advindas dos meios de comunicação de massa, destacadamente, televisão e internet -, com as quais os indivíduos tinham de conviver não era tão ampla quanto a que nos deparamos hoje, onde a multiplicidade de vozes normativas em relação à alimentação parece resultar em voz alguma, inserindo-nos num cenário de mal-estar, incerteza e ansiedade. Uma anomia em direção à falta ou ao excesso.

A paródia de Botero, intitulada Matrimonio Arnolfini segun van Eyck, 1978, traz à tona corpos voluptuosos. Leituras podem ser feitas. Teria o uso destas formas apenas um caráter estético? Quando questionado sobre o motivo de pintar figuras obesas, Botero respondeu que não pintava pessoas gordas. O artista pontua seu estilo como estratégia estética e de formação de estilo, frustrando assim muitos que esperavam em seu discurso uma breve análise do lugar dos corpos obesos na sociedade atual. Evocaria ela à riqueza, à saúde e à sensualidade como até pouco tempo na América Latina era vista a gordura? ${ }^{19}$ Corpos voluptuosos? Corpos obesos? ${ }^{20}$ A leitura da obra de arte, para além do propósito do autor depende também daquele que lê. Sendo assim, podemos chegar a múltiplas leituras e, numa delas, enxergar as formas na arte do colombiano Fernando Botero como uma referência ao excesso: ao excesso de complacência de um mundo que já não lida mais com regras, mas com uma cacofonia irritante, excesso de informações. "O excesso abafa a informação [...] enquanto a informação dá forma às coisas, a superinformação nos submerge no informe", diria Morin ${ }^{21}$ (p.21). Esse é o cenário no qual estão inseridos os Arnolfini de Botero. Os personagens, apesar de obesos, parecem estar prontos para flutuar devido à leveza do traço que pinta suas peles, traço marcante de uma sociedade fluida, onde a anomia assemelha-se mais à leveza que à solidez. Uma modernidade líquida? Os olhares e gestos não nos transmitem emoção. A obra de Botero é isenta de comentários emo- 
cionais ${ }^{22}$. O excesso de complacência, fruto do excesso de discursos, gera corpos desmedidos: a sociedade do excesso. Através das lentes de alguém que tenta problematizar a crise na alimentação contemporânea este é o mundo do excesso que podemos encontrar em Botero.

É na brecha da anomia que florescem as pressões sobre o comensal moderno. A alimentação passa a constituir um campo de decisões pessoais que é alimentado por uma diversidade de normas que são dissonantes: higienistas, identitárias, hedonistas, estéticas ${ }^{23}$. Há um rompimento da unanimidade de opiniões que arranca o sujeito da reprodução de normas costumeiras. Os comensais já não dispõem de conceitos reguladores. O corpo carrega estampada a marca deste mal-estar, que parece repousar sobre o excesso de informações. Recente pesquisa realizada por Claude Fischler, ao tentar investigar o que é comer bem para algumas populações de países distintos, constatou que ainda que os estadunidenses, mais que os europeus, relatem que hoje "é fácil encontrar qualquer informação da qual se necessite para comer de forma sadia" 24 (p.93), são eles os mesmos que acreditam que comem de forma menos saudável. Fischler, que cunhou o conceito de gastro-anomia, levanta a seguinte questão: "muita informação mata a informação?" 24 (p.94).

Em nossa sociedade a informação referente à alimentação assume formas assustadoras que alimentam a gastro-anomia. Nunca se produziu tanta informação com referência ao tema da comida. Embora a lista dos dez livros mais vendidos nos Estados Unidos da América (EUA) mude a cada semana, "dois tipos de publicação aparecem invariavelmente: obras de culinária que oferecem receitas de pratos cada vez mais refinados, deliciosos e sedutores e manuais de dieta prometendo regimes cada vez mais infalíveis para produzir corpos livres de gordura, esbeltos e graciosos" 25 (p.117). A vida dos comensais passa a ser uma experimentação contínua carregada de incertezas. Vivemos uma situação de "pânico alimen$\operatorname{tar}^{\prime \prime 25}$ (p.95).
Tão incômodo é o cenário que na mesma pesquisa de Claude Fischler ${ }^{25}$ as pessoas da maior parte dos países onde foram realizadas as entrevistas demonstraram desejo de abrir mão da tarefa de escolher. Afastá-la-iam para não terem que lidar com o "fantasma da liberdade"? Durante o estudo, foram propostas duas questões às pessoas:

primeira: Você está com vontade de tomar um sorvete e tem de escolher entre duas sorveterias. A primeira oferece cinquenta sabores diferentes; a segunda, uma seleção de dez sabores. O preço é o mesmo, qual você escolheria?

segunda: Você foi convidado para jantar em um grande restaurante. O que prefere? Um cardápio com uma grande variedade de pratos ou um pequeno número de sugestões escolhidas pelo chef? (p.93).

De todos os países investigados apenas nos EUA as pessoas prefeririam o longo cardápio e a sorveteria com cinquenta sabores. Os outros optaram pela pré-seleção e por menos opções para lidarem.

Em seus contextos sociais, os Arnolfini de Botero teriam de lidar com uma quantidade de informações bem maior do que o casal de van Eyck teria de gerenciar. Além da multiplicidade de discursos, aqueles que ofereceriam um porto seguro frente às incertezas da anomia se apresentariam mais frouxos. Tomemos como exemplo o lugar da religião: comparativamente à Idade Média, hoje não cumpre um papel de estruturação hegemônica na sociedade ${ }^{26}$. Não por coincidência, o tema apresenta-se timidamente na paródia do artista colombiano. O espelho rebuscado dá lugar a um simples espelho arredondado, fazendo desaparecer a referência às passagens bíblicas em seu redor. As laranjas, símbolo de pureza, dividem a cena com maçãs: fruto que a partir do século XIII, segundo Zierer passou a ser a principal representação do pecado de Adão e Eva no jardim do Éden ${ }^{27}$. A senhora Arnolfini, rompendo com a "regra" cristã da castidade 
aparece grávida no momento de celebração da boda. Na obra original, ainda que a noiva aparente ter o ventre um pouco abaulado, um olhar mais cuidadoso revela-nos que a senhora sim, parece apenas estar puxando a saia do vestido para a zona da barriga, o que causaria o volume na região. Essa era a moda da época. Imersos no excesso, teriam os Arnolfini de Botero de lidar com mais pontos de incerteza? Aparentemente, sim.

\section{Pensar para, pensar com}

Os quadros do colombiano Botero parecem um retrato dos corpos que vemos no espelho e nas ruas. Percebemo-nos diariamente mergulhados num excesso desconcertante. A gastro-anomia instalou-se dentro de nós. Acompanha-nos desde as prateleiras do supermercado ao momento de levar o alimento à boca. A liberdade e a restrição, como nunca antes, travam a luta do equilíbrio no controle individual dos corpos. Carecemos de normas. De um discurso que nos diga por onde caminhar. O que comer? Como comer? Perguntas que ecoam diariamente na cabeça de nossa sociedade.

Quanto mais inseguros, mais vemos florescer a multiplicidade de discursos oferecidos pelo mercado para "ajudar" a lidar com nossos medos dietéticos: dieta da lua, de Atkins, de South Beach, do paleolítico, do mediterrâneo, shakes e chás que prometem perda de peso imediato e cobram caro por isso. E nós? Nós compramos.

O discurso da ciência da Nutrição é mais um dos milhares com que se depara o comensal contemporâneo em sua busca pelo "comer bem". Ainda que esta seja uma mensagem que carrega o selo "científico", paradigma hegemônico da sociedade atual, não esqueçamos que muito ainda há a se pensar. Qual é a linha entre norma e excesso? O que é saúde? O que é comer bem? Como diria Durkheim, o progresso de uma ciência pode ser percebido "pelo fato de as questões de que ela trata já não permanecerem estacionadas" $^{4}$ (p.1). O que fazemos destas novas ques- tões? Debruçamo-nos sobre elas? Pensamo-las junto aos comensais? Ou, ao contrário, nos limitamos a oferecer mais um discurso pronto às pessoas.

Devido ao sem fim de fatores que transpassam a alimentação, talvez não consigamos chegar a uma teoria alimentar que sintetize o bem comer. E, em verdade, esse talvez não devesse ser o propósito da Nutrição. O papel do nutricionista na sociedade atual deveria ser não o de pensar a alimentação para as pessoas - fornecendo-lhes fórmulas prontas para seus questionamentos - mas, pensar a alimentação com as pessoas, ajudando-as a lidar com a avalanche de informações com as quais se deparam, para que assim, possam constituir-se sujeitos de suas escolhas.

\section{COLABORADORES}

M MEDEIROS contribuiu com a redação inicial do artigo, na discussão da gastro-anomia pelas obras de arte e na revisão final do artigo. A GALENO contribuiu no aprofundamento sociológico do conceito de anomia, na discussão sobre medicina na Idade Média e na revisão do artigo.

\section{REFERÊ NCIAS}

1. World Health Organization. Obesity and overweight. Geneva: WHO; 2011 [cited 2011 May 24]. Available from: <http://www.who.int/mediacentre/factsheets/ fs311/en/index.html>.

2. Instituto Brasileiro de Geografia e Estatística. Pesquisa de orçamentos familiares 2008-2009. Antropometria e estado nutricional de crianças, adolescentes e adultos no Brasil: análise dos resultados. Brasilia: IBGE; 2010 [acesso 2012 nov 13]. p.23. Disponível em: <http://www.ibge.gov.br/home/ estatistica/populacao/condicaodevida/pof/2008_ 2009_encaa/comentario.pdf>.

3. Fischler, C. El (h)omnívoro: el gusto, la cocina y el cuerpo. Barcelona: Editorial Anagrama; 1995.

4. Durkheim E. O suicídio anômico In: O suicídio. São Paulo: Martins Fontes; 2000.

5. Durkheim E. A divisão do trabalho social. $2^{\text {a }}$ ed. Lisboa: Presença; 1984. Vol. 2. 
472 M MEDEIROS \& A GALENO

6. Durkheim E. Educação e sociologia. $10^{\mathrm{a}}$ ed. São Paulo: Melhoramentos; 1978.

7. Goldenberg M. Cultura e gastro-anomia: psicopatologia da alimentação cotidiana. Entrevista com Claude Fischler. Horiz Antropol. 2011 [acesso 2012 nov 13]; 17(36):235-56. Disponível em: <http:// www.scielo.br/ha>. doi: 10.1590/s0104-7183 2011000200010.

8. Lévi-Strauss CL, Eribon D. De perto e de longe. São Paulo: Cosac Naify; 2005.

9. Morin E. A cabeça bem-feita. $14^{a}$ ed. Rio de Janeiro: Bertrand Brasil; 2008.

10. Lévi-Strauss C. O pensamento selvagem. $11^{\text {a }}$ ed. Campinas: Papirus; 1989.

11. Gombrich EH. A história da Arte. $16^{\mathrm{a}}$ ed. Rio de Janeiro: LTC; 1999. p.240.

12. Le Breton D. Adeus ao corpo: antropologia e sociedade. São Paulo: Papirus; 2003.

13. Laurioux B. Manger au Moyen Âge. Paris: Hachette Littératures; 2002.

14. Serafim SSB. Estudo iconográfico da representação dos cães na arte [monografia]. Criciúma: Universidade do Extremo Sul Catarinense; 2012.

15. Tainha R. À descoberta do casal Arnolfini: atividades destinadas aos alunos do terceiro ciclo. 2010 [acesso 2011 maio 22]. Disponível em: <http:// www.min-edu.pt/data/Noesis/noesis_destacavel82 bx.pdf>

16. Jung CG. O espírito na arte e na ciência. $6^{a}$ ed. São Paulo: Vozes; 2011. p.19.
17. Laurioux B. Manger au Moyen Âge. Paris: Hachette Littératures; 2002.

18. Lévy P. As tecnologias da inteligência: o futuro do pensamento na era da informática. São Paulo: Editora 34; 1995.

19. Kalenberg A. Una raza de gordos: sobre la pintura de Fernando Botero. Rev Dossier. 2008 [acesso 2012 nov 13]; 2(7):5-13. Disponible en: <http://www. revistadossier.com.uy/content/view/201/160/>.

20. Woodhouse R. Obesity in art: A brief overview. Front Horm Res. 2008; 36(1):271-86.

21. Morin E. Para sair do século XX. Rio de Janeiro: Nova Fronteira; 1986. p.31.

22. Hanstein M. Fernando Botero. Alemanha: Taschen; 2003.

23. Arnaiz MG. Paradojas de la alimentación contemporánea. Barcelona: Icaria Editorial; 1997.

24. Fischler C, Masson E. Comer: a alimentação de franceses, outros europeus e americanos. São Paulo: Senac; 2010. p.93-8.

25. Bauman Z. Vida líquida. $2^{\text {a }}$ ed. Rio de Janeiro: Jorge Zahar; 2009. p.93-8.

26. Giddens A. As consequências da modernidade. São Paulo: Unesp; 1991.

27. Zerer A. Significados medievais da maçã: fruto proibido, fonte do conhecimento, ilha Paradisíaca. Mirabilia. 2001; 1(1):104-19.

Recebido em: 11/4/2012 Versão Final em: 4/2/2013 Aprovado: 25/4/2013 